\title{
Translating Neuronal Activity into Dendrite Elaboration: Signaling to the Nucleus
}

\author{
Lori Redmond \\ Department of Pharmacology and Toxicology, Medical College of Georgia, Augusta, Ga., USA
}

\section{Key Words}

Dendrite development $\cdot$ Dendrite elaboration $\cdot$ Calcium signaling $\cdot$ Calmodulin-dependent protein kinases $\cdot$ Mitogen-activated protein kinase - cAMP-responsive element-binding protein $\cdot$ Calcium-dependent transcription

\begin{abstract}
Growth and elaboration of neuronal processes is key to establishing neuronal connectivity critical for an optimally functioning nervous system. Neuronal activity clearly influences neuronal connectivity and does so via intracellular calcium signaling. A number of CaMKs and MAPKs convey the calcium signal initiated by neuronal activity. Several of these kinases interact with substrates in close proximity to the plasma membrane and alter dendrite structure locally via these local interactions. However, many calcium-activated kinases, such as Ras-MAPK and CaMKIV, target proteins in the nucleus, either by activating a downstream substrate that is a component of a signaling cascade or by directly acting within the nucleus. It is the activation of nuclear signaling and gene transcription that is thought to mediate global changes in dendrite complexity. The identification of calcium-sensitive transcription factors and transcriptional coactivators provides substantial evidence that gene transcription is a prevalent mechanism by which neuronal activity is translated into changes in dendrite complexity. The present review presents an overview of the role of neuronal activity
\end{abstract}

in the development of neuronal dendrites, the signaling mechanisms that translate neuronal activity into gene transcription, and the transcribed effectors that regulate dendrite complexity.

Copyright $\odot 2008$ S. Karger AG, Basel

\section{Introduction}

The mammalian cerebral cortex is divided into multiple areas based on the function served and ranging from primary sensory regions where sensory information of the external world is first received to regions where sensory information is integrated and behavior determined. For the cortex to process sensory information into a behavior, appropriate connections between neurons must be established and maintained. The pattern of dendrite arborization a neuron exhibits is tightly correlated to neuronal function, so much so that a neuron is identified based on its morphology. Two general morphologically defined neurons, pyramidal and nonpyramidal, compose the cerebral cortex. These two general classes have distinct dendrite morphology, circuitry, neurotransmitter phenotype, and laminar position. This morphological diversity has several functional consequences including determining electrophysiological properties and afferent partners with which the neuron can interact [reviewed in 1-3].

The developmental events that occur in establishing morphological diversity and neuronal connectivity pro-

Dr. Lori Redmond

Department of Pharmacology and Toxicology CB3530

1120 15th Street, Medical College of Georgia

Augusta, GA 30912 (USA)

E-Mail karger@karger.ch Accessible online at:

www.karger.com www.karger.com/nsg

Tel. +1 706721 0906, Fax +1 706721 2347, E-Mail lredmond@mail.mcg.edu 
ceed in two general phases. First, the cells are generated. Second, these cells differentiate into mature neurons acquiring different biochemical, electrophysiological and morphological properties essential for proper functioning [reviewed in 2-4]. It is in this second phase of maturation that intrinsic and extrinsic signals have the greatest influence on the maturing neurons' morphology and connectivity. Although the final dendrite arbor is distinct between neurons, dendrite development proceeds through identical stages in this second phase. Establishment of neuronal morphology begins shortly after the neuron becomes postmitotic and involves four distinguishable stages in sequential progression. These include initiation, growth (lengthening), branching, and dendrite spine formation [reviewed in 5]. Initiated processes grow from the soma after which molecular guidance mechanisms establish polarity by determining the axon from the dendrite processes $[6,7]$. Subsequently, dendrites grow in length, form branches, and in most cell types generate dendrite spines.

These stages of dendrite development are clearly illustrated by neurons in the developing rodent cortex. During the first postnatal week both pyramidal and nonpyramidal neurons undergo extensive dendrite growth, branching, and elaboration [8-11]. Dendrite tree size and complexity continues to increase in the second and third postnatal week but at a slower rate $[8,9]$. Dendrite spines, the major locations of excitatory synaptic contact, begin to appear en masse during the second and third postnatal weeks [8]. The first spines, seen at 1-4 weeks postnatally, are long and thin and resemble filopodia [12-14]. As dendrite spines mature, this filopodial appearance changes and the spines acquire a bulbous ending or 'head' and shorten $[8,13,14]$. At the conclusion of the stages of dendrite growth, a neuron exhibits an exuberant dendrite tree, which has a greater potential for connectivity with afferents. However, there are examples where these exuberant dendrite arbors are reorganized. For instance, the organization of dendrites of neurons that compose a glomerulus, such as those in the olfactory bulb and somatosensory cortex, become biased so that interaction with afferent axons is maximal $[15,16]$.

\section{Role of Activity in Development of Dendrite Architecture}

A major question in the process of dendrite development and complexity is whether neuronal activity plays a role and, if so, how it contributes to the mature dendrite pattern. On the one hand, basic organization of the brain can occur in the absence of activity via neurotransmitter release [17]. In addition, thalamic axons segregate into columns prior to visual stimulation [18]. Further, in vivo Golgi labeling studies indicated basic features of pyramidal neuronal morphology were established prior to the arrival of afferent fibers [11]. However, it is becoming increasingly apparent that activity influences multiple aspects of dendrite development. The concurrent timing of axonal innervation and dendrite elaboration hints of a relationship between the two processes. For instance, as afferent fibers arrive and establish adult like distribution patterns, pyramidal dendrites elaborate and dendrite spines form [8-11]. This also appears to be the case in retinotectal innervation in Xenopus $[19,20]$.

Activity deprivation experiments also suggest that normal neuronal activity during development plays a critical role in dendrite development. Several studies have demonstrated that blocked or attenuated activity leads to lasting deficits in dendrite arborization. Pharmacological blockade of synaptic activity led to deficits in dendrite growth in Xenopus tectal neurons [21]. Monocular deprivation in mammals also altered dendrite development in the lateral geniculate nucleus and the visual cortex [22, 23]. As in the visual system, dendrite arbors of neurons that lie in the somatosensory cortex were altered by changes in afferent input $[24,25]$. Normal locomotor activity also appeared to be important for motor neuron dendrite elaboration [26]. Aberrant granule cell migration and loss, disrupted normal afferent input onto Purkinje neurons and resulted in dramatically attenuated Purkinje dendrite arbors [27, 28]. Inhibition of spontaneous activity with pharmacological agents in in vitro slice cultures and in dissociated neurons also results in attenuation of dendrite growth [29]. In addition, neuronal activity has been shown to play an important role in dendrite spine dynamics and formation [30, 31].

In contrast, increasing activity by exposing animals to enriched environments enhanced dendrite branching and spine density of cortical pyramidal neurons [32-34]. After exposure to light for $4 \mathrm{~h}$ dendrite arbors of tectal neurons were more extensive than those not exposed to light [35]. In fact, even short transient episodes of sensory input had pronounced and prolonged effects on dendrite elaboration [35]. In vitro studies also demonstrated that neurons in which activity is increased by pharmacological manipulations exhibit significantly greater dendrite complexity. For instance, increases in glutamate signaling or activation of calcium channels resulted in dendrite arbors that were significantly more elaborate both in dis- 
sociate neuronal preparations as well as organotypic cortical slice cultures [29, 36-39]. A role for neuronal activity in the control of dendrite development is not restricted to cortical pyramidal neurons but has also been implicated in multiple neuronal systems [40-46].

Although activity-induced changes in dendrite structure may be most pronounced during development [46], activity-induced changes in dendrite structure have been reported outside the confines of a developmental time window. In vivo and in vitro studies using cellular models of plasticity indicate that long-term potentiation (LTP) induces structural changes in parallel to the induced changes in synaptic efficacy. For instance, induction of LTP in vivo in adult rats resulted in increased spine density and apical dendrite branching [47]. In Aplysia, activity that resulted in long-term facilitation also induced new synaptic growth [48]. This influence of activity on dendrite elaboration is not limited to rodents and Aplysia, but was also seen in the adult nonhuman primate. Kozorovitskiy et al. [49] housed adult marmosets, ranging from 1.5 to 5.5 years in age, in an enriched environment for a month. After this relatively short exposure, not only were dendrite spine densities increased, but the apical and basal dendrites of hippocampal and cortical pyramidal neurons also increased significantly in length and branching [49].

\section{Membrane Receptors and Calcium Influx}

The mechanism by which activity conveys information to the receiving neuron is without doubt complex. Ever since the identification that neurons conveyed information via changes in ions across their membranes, the pursuit to identify the mechanisms involved and the functional consequences has been intense [50]. Numerous studies have demonstrated that calcium flux across the membrane is key to neurotransmission. Extracellular and intracellular calcium levels are dramatically different in neurons in resting conditions; extracellular calcium levels are approximately 20,000-fold greater than in the cytoplasm. Neuronal activity leads to changes in intracellular calcium levels through two mechanisms. Cytosolic calcium is increased by release from intracellular stores and entry of extracellular calcium via plasma membrane calcium channels and calcium-permeable receptors. Calcium release from intracellular stores has been shown to act locally to stabilize dendrite structure [51] and influence the mobility of dendrite filopodia [52]. However, influx of extracellular calcium activates signal- ing cascades that control transcriptional regulation of the dendrite arbor and these global signaling events will be the focus of this review.

Although there are several sites of calcium entry into cells, the two principal sites in neurons are voltage-sensitive calcium channels (VSCCs) and ionotropic glutamate receptors [reviewed in 50, 53-55]. The N-methyl-D-aspartate (NMDA) receptor and L-type VSCC have specifically been identified as key channels conveying neuronal activity from the presynaptic neuron into calcium influx in the postsynaptic neuron. These channels are key players in mediating numerous postsynaptic neuronal functions, which are reviewed elsewhere [56]. In this review, discussion will be limited to the role of VSCCs and ionotropic glutamate receptors in mediating morphological changes.

Studies in the Xenopus retinotectal system have demonstrated that signaling via glutamate receptors is crucial for normal tectal cell dendrite arborization throughout the elaboration and development of the dendrite arbor [21]. Blockade of NMDA receptors, but not alpha-amino3-hydroxy-5-methyl-4-isoxazole proprionate (AMPA) receptors in the early stage of tectal cell dendrite development resulted in a failure in the addition of new branches and the elongation of preexisting branches. However, blockade of NMDA and AMPA receptors at later stages of dendrite elaboration decreased dendrite arbor branch length [21]. This indicates that early dendrite development in the Xenopus retinotectal system relies on NMDAmediated mechanisms while later in dendrite development AMPA receptors also play a role. Developing postnatal motor neurons also rely on glutamate signaling via the NMDA receptor for dendrite elaboration [46]. Pharmacological blockade of NMDA receptors in vivo with either 2-amino-5-phosphovalerate (APV) or MK-801, attenuated motor neuron dendrite arborization by 40 and $60 \%$, respectively [46]. However, AMPA receptor subunits are highly expressed in developing motor neurons [57]. When subunits of the AMPA receptor (GluR1) were overexpressed in motor neurons in vivo the complexity of dendrite arbors was modified by changes in the relative balance of branching and dendrite number and not a change in dendrite length [58]. These in vivo studies suggest that both NMDA and AMPA receptors are important for mediating dendrite elaboration, but that NMDA receptors may contribute more to increasing the size of the dendrite arbor.

In addition to glutamate receptors mediating a role in basal (constitutive) development of dendrite arbors, evidence from in vivo and in vitro studies indicate glutamate 
receptors are critical for activity-induced changes in dendrite elaboration. In the Xenopus visual system, exposure of the animals to light led to significant increases in the arborization of tectal neuron dendrites [35]. Pharmacological blockade of NMDA and AMPA glutamate receptors prevented the dendrite elaboration induced by visual stimulation. This indicates that physiological activity-induced dendrite elaboration was dependent on glutamate receptor signaling [35]. Erzurumlu and colleagues [59, 60] examined animals in which the NR1 subunit of the NMDA receptor was specifically removed in the cortex of mice and showed that the NMDA receptor was also critical for dendrite arbors to restructure in response to neuronal activity [60]. In addition, the ability of spontaneous activity in vivo to enhance dendrite elaboration was dependent on signaling via NMDA receptors $[29,39]$.

In other systems, it appears that calcium influx via VSCCs plays a more significant role than calcium influx via glutamate receptors in activating dendrite elaboration. In cortical neurons dendrite growth could be stimulated with glutamate to activate NMDA receptors and $\mathrm{KCl}$ to open VSCCs; however, dendrite elaboration was most dramatic after VSCC activation. In addition, activity-induced growth specifically depended on calcium influx via activation of the L-type of VSCC and not the NMDA receptor [29]. It also appears that VSCCs but not NMDA receptors function in mediating basal levels of dendrite growth in dissociated and in vitro slice preparations of cortical neurons [29].

VSCCs and glutamate receptors can be downstream of other signaling mechanisms to mediate changes in dendrite arborization. For example, hepatocyte growth factor (HGF) induced a dose-dependent increase in total dendrite branch tip number and total dendrite branch length in hippocampal neurons. The ability of HGF to induce dendrite elaboration was blocked with APV indicating a requirement for NMDA receptor activity [61]. As with NMDA receptors, L-type VSCCs have been shown to act downstream of signaling mechanisms that induce changes in dendrite arbors. For instance, blocking L-type VSCCs inhibited GABA-activated dendrite elaboration of cerebellar granule neurons [62].

Numerous proteins interact with VSCCs and glutamate receptors and modulate channel localization or function $[56,63,64]$. However, VSCCs and NMDA receptors mediate an effect on activity-dependent signaling and dendrite elaboration by calcium influx. Numerous studies have shown that calcium enters neurons via Ltype VSCCs and NMDA receptors [50, 53, 54]. Chelating extracellular calcium with EGTA to prevent calcium from entering the neuron blocked activity-induced dendrite growth of cortical neurons, indicating calcium influx was required. In fact, the magnitude of the effect of blocking calcium entry on dendrite elaboration was the same as that of blocking VSCCs [29].

\section{Activation of Intracellular Signaling Pathways}

Once inside the neuron, what happens to calcium? Ultimately membrane-associated $\mathrm{Ca}^{2+}$ adenosine triphosphatases pump calcium out of the neuron into the extracellular space or into intracellular calcium stores, such as the endoplasmic reticulum. Before calcium is removed from the cytoplasm, however, it acts as an intracellular signal. Calcium influx will have the most immediate effect on signaling molecules located in the submembrane compartment. In fact, Hardingham et al. [65] have shown that submembrane microdomains of intracellular calcium, rather than global changes in intracellular calcium, were sufficient to activate some, although not all, intracellular signaling events. Global and even nuclear calcium changes have been shown to be important in mediating activity-induced changes in, for example, gene transcription $[65,66]$.

When calcium enters the cytoplasm it is readily bound by proteins that contain calcium binding domains [reviewed in 64]. Calmodulin is a calcium-binding protein present in neurons that is also located in the submembrane region near channel pores where it functions as a local calcium sensor. Calmodulin also interacts directly with numerous proteins present in the submembrane compartment. For instance, calmodulin binds the NR1 subunit of the NMDA receptor [67] and two different regions of the alpha subunit of the L-type VSCC [reviewed in 63,68$]$. Pharmacological inhibition of calmodulin had the same effect on morphology as did blocking calcium influx or ion channel function $[69,70]$. Together, these studies indicate that calmodulin is an important mediator of calcium-dependent signaling.

Calmodulin binds several cytoplasmic proteins including calcium/calmodulin-dependent protein kinases (CaMKs), protein phosphatases, and adenylyl cyclases. All three signaling pathways that are activated in response to calcium influx via VSCCs and ionotropic glutamate receptors, the CaMKs, the mitogen-activated protein kinases (MAPKs) and adenylyl cyclase-protein kinase A (PKA) [reviewed in 53, 55], interact with calcium/calmodulin. When activated by calcium binding calcium-bound calmodulin (CaM), subsequently binds 
and activates a number of CaMKs [reviewed in 71, 72]. Once bound by CaM, CaMKs autophosphorylate and enter an active state that becomes CaM independent. In addition to activation by CaM, CaMKI and CaMKIV can be phosphorylated by CaMK kinase (CaMKK) [71-73].

Although the mechanism is not as clearly defined, calmodulin is also necessary for activation of the RasMAPK pathway [68]. Early studies demonstrated that calcium influx via L-type VSCCs-activated Ras which preceded and was necessary for MAPK/ERK kinase (MEK) activation [74]. Several potential mechanisms have been identified that may mediate calcium activation of Ras [reviewed in 75]. Calcium regulates the exchange activity of Ras-GRFs (Ras-guanine-nucleotide-releasing factors). It is thought that this regulation is via calmodulin binding to the IQ domain of Ras-GRFs. When the IQ domain is mutated, calcium is unable to activate RasGRF. In addition, Ras-GRPs (Ras-guanine-nucleotidereleasing proteins) directly bind calcium via EF-hand domain and thus may be regulated by calcium directly.

In addition to the CaMK and the Ras-MAPK pathways, the activity of two adenylyl cyclases, type 1 and type 8 adenylyl cyclases ( $\mathrm{AC} 1$ and $\mathrm{AC} 8$ ), is stimulated by $\mathrm{CaM}$ [reviewed in 76]. Both contain domains that bind $\mathrm{CaM}$ that are necessary for activation via $\mathrm{CaM}$. $\mathrm{AC} 1$ and AC8 are different in their sensitivity to intracellular calcium. While AC8 responds to high intracellular concentrations of calcium $(800 \mathrm{nM}), \mathrm{AC} 1$ is approximately 5 -fold more sensitive to calcium than AC8. Of these three pathways, evidence suggests that the CaMK and MAPK pathways play a more prominent role in mediating activityinduced dendrite elaboration. For example, inhibiting either CaMK or MAPK activity but not PKA attenuated cortical neuron dendrite growth [29]. Even though a clear role for adenylyl cyclases in dendrite elaboration is lacking, layer 4 neurons in the somatosensory cortex of $\mathrm{AC} 1$ but not AC8 mutant animals failed to form proper barrel structures [77, 78]. Further study of adenylyl cyclases may reveal whether and how $\mathrm{AC} 1$ and $\mathrm{AC} 8$ regulate dendrite elaboration.

It is often difficult to tease out the contribution of CaMK and MAPK signaling pathways to dendrite elaboration. In many cases both are activated and required to mediate calcium-induced changes in dendrites. For instance, the degree of cortical neuron dendrite growth attenuated by blocking CaMK and MAPK pathways was similar to that detected when VSCCs were inhibited [29]. In addition to a role in basal dendrite growth of cortical neurons, the CaMK and MAPK pathways also mediate activity-induced dendrite growth in cortical neurons and hippocampal neurons [29, 39]. GABA induced dendrite elaboration (via L-type VSCCs) of cerebellar granule neurons, as well as activity-induced dendrite growth of sympathetic neurons, was also blocked by pharmacological inhibition of either CaMKs or MAPKs [36, 62]. These results indicate that both CaMK and MAPK pathways play a conserved role in mediating activity-induced dendrite elaboration.

Localization studies, however, have hinted that there may be some selectivity in the intracellular signaling pathways activated. L-type VSCCs are enriched at the base of apical dendrites [79]. This places VSCCs in close proximity to the nucleus where calcium influx might be expected to influence nuclear events. In addition, receptors form complexes with a number of intracellular proteins through protein-protein interaction domains present in their cytoplasmic regions [reviewed in 56]. Considering elevation of calcium in submembrane microdomains was sufficient to activate intracellular signaling events [80], localized calcium influx would be expected to activate proteins in close proximity of the channel and initiate a cascade of signaling events that would be most effective within a localized area. In this manner, differences in channel localization have been proposed to contribute to selectivity in the intracellular signaling pathways activated.

More convincing evidence comes from signaling studies that demonstrated that the mode of calcium entry (i.e. channel) played a significant role in controlling the signaling pathways activated. Bading et al. [70] found that inhibition of calmodulin signaling inhibited depolarization-induced transcription, but it did not inhibit transcription activated by glutamate. These results suggested that two different signaling pathways were activated preferentially by VSCCs and NMDA receptors to induce transcription [70]. Further, activation of VSCCs and glutamate receptors induced dendrite growth of cortical neurons, however the efficacy induced via VSCCs surpassed that of glutamate receptors [29]. This suggests that calcium influx via VSCCs and NMDA receptors is different in its ability to activate signaling mechanisms that induce dendrite growth.

\section{Molecules Implicated in Calcium-Dependent Dendrite Growth: CaMKs and MAPKs to the Nucleus}

Of the CaM kinases, CaMKII has been the most extensively studied in relation to a role in function and signaling in dendrites [reviewed in 71, 81]. CaMKII $\alpha$, the 
most extensively studied of the four isoforms, is expressed at later stages of dendrite elaboration and is localized in the cytoplasm $[29,69]$. In Xenopus tectal neurons, active CaMKII $\alpha$ slowed the rate of dendrite growth in young neurons, which led to significantly attenuated dendrite arbors. When mature neurons expressed active CaMKII $\alpha$, their dendrites displayed less dynamic process additions and retractions [82]. Blocking CaMKII with AIP, a peptide that specifically inhibits CaMKII, in mature neurons increased the length of dendrite branches. These data indicated that CaMKII $\alpha$ stabilized dendrite arbors of mature neurons, and restricted growth of tectal dendrites irrespective of neuronal maturity [82, 83]. In cortical neurons active forms of CaMKII $\alpha$ similarly limited dendrite growth [29]. However, studies have indicated that CaMKII also has growth promoting roles. Inhibition of CaMKII with AIP inhibited activity-induced dendrite growth of sympathetic neurons [36]. Likewise, attenuation of CaMK activity either by pharmacological blockade or RNAi knockdown of CaMKII $\alpha$ decreased dendrite length of cerebellar granule neurons $[38,62]$. These results suggest that CaMKII regulation of dendrite arbors may be temporally and cell-type specific.

Of the other isoforms of CaMKII, the role of CaMKII $\beta$ in dendrite elaboration of hippocampal neurons has been examined. When expressed, CaMKII $\beta$, and not CaMKII $\alpha$ increased dendrite filopodia motility and branching at 3 days in vitro (DIV) [69]. This resulted in more extensive dendrites as measured by the perimeter of the dendrite arbor. The ability of CaMKII $\beta$ to promote an increase in dendrites decreased with age and by 11 DIV had an inhibitory effect. CaMKII $\beta$ action was dependent on an interaction with actin and indicated that CaMKII $\beta$ mediated an increase in dendrites by a local signaling mechanism [69].

Unlike CaMKII, CaMKIV expression is upregulated during the peak period of dendrite development and is nuclearly localized $[29,84]$. Contrary to the effect of CaMKII $\alpha$, CaMKIV induced significant elaboration of dendrites when expressed in cortical neurons. Active forms of CaMKIV mimicked activity-induced dendrite growth and expression of wild type CaMKIV potentiated activity-induced dendrite growth. When endogenous CaMKIV was inhibited by expression of kinase dead CaMKIV (KD CaMKIV) activity-induced dendrite growth was attenuated. Others have also reported that CaMKIV expression in hippocampal neurons increased dendrite elaboration [37] and dominant negative CaMKIV (DN CaMKIV) expression decreased dendrite complexity [85]. However, when a nuclear localization sequence (NLS) was attached to DN CaMKIV (DN CaMKIV NLS) to ensure nuclear localization, no significant effect on basal or activity-dependent dendrite growth was detected [39, 85]. Yet, when Kamata et al. [86] expressed KD CaMKIV NLS in hippocampal neurons in basal conditions they reported a $25 \%$ decrease in total dendrite length and a $30 \%$ decrease in the number of primary dendrites. While it is unclear why the results of these two studies using CaMKIV NLS are not the same, it is possible that the duration of expression and efficacy of constructs as inhibitors of endogenous CaMKIV contributed to the disparity.

These two research groups also report a difference in the contribution of CaMKK signaling to hippocampal dendrite elaboration in basal conditions. Using the pharmacological inhibitor STO-609 at the dose specific for CaMKK, Kamata et al. [86] report a 32\% decrease in total dendrite length and a $28 \%$ decrease in primary dendrites of hippocampal neurons under basal conditions. Expression of $\mathrm{KD}$ CaMKK $\alpha$ resulted in a similar decrease in total dendrite length (25\%) and decrease in the number of primary dendrites (27\%) [86]. Wayman et al. [85] also report a significant decrease in the total length of hippocampal processes (axons and dendrites) after STO-609 treatment that expression of DN CaMKK mimics. Although DN CaMKK also decreased the number of primary processes as well as length [85], when dendrites were specifically examined, however, an effect of STO609 on dendrite arbors was not detected [39]. Yet, when coexpressed with CaMKI, active CaMKK increased the number of neurites on NG108 cells [87], indicating that CaMKK is sufficient to induce neurite formation.

While the contribution of CaMKK to basal (or constitutive) dendrite elaboration is not entirely clear, Wayman et al. $[39,87]$ have shown that CaMKK is critical for mediating activity-dependent dendrite elaboration via activation of CaMKI. Two of the four isoforms of CaMKI, $\alpha$ and $\gamma$, have been implicated in mediating dendrite elaboration. CaMKI $\alpha$ contains a nuclear export sequence that retains it in the cytoplasm $[88,89]$. Active CaMKI $\alpha$ increased total dendrite length of hippocampal neurons as well as length of hippocampal axons and number of processes of N2A cells $[39,90]$. Inhibiting CaMKI $\alpha$ with either dominant negative CaMKI $\alpha$ or siRNA knockdown of CaMKI $\alpha$, attenuated activity-induced increase in dendrite length. siRNA knockdown of CaMKI $\gamma$, but not siRNA of CaMKI $\beta$ or CaMKI $\delta$, also attenuated activityinduced increase in dendrite length [39]. 
Through a series of inhibition experiments, it was demonstrated that CaMKI mediates activity-induced dendrite growth via activation of the MAPK signaling pathway. However an alternate signaling mechanism by which CaMKI $\alpha$ can influence morphology has been described. Uboha et al. [90] have identified that MARK2/ Par-1b (microtubule affinity regulating kinase 2) binds CaMKI, is expressed in hippocampal neurons, and is a CaMKI substrate. In this study, kinase dead MARK2 inhibited active CaMKI $\alpha$ induction of hippocampal axon lengthening. Further, MARK2-induced hippocampal axon length was attenuated by STO-609. Whether MARK2 activated MAPK signaling or functions in an activity-dependent manner, as does CaMKI $\alpha$, has not been determined. Although dendrites were not examined, the contribution of MARK2 to dendrite formation may lend insight into the signaling mechanisms by which CaMKI affects axon and dendrite elaboration.

In a detailed study of CaMKI $\gamma$, Takemoto et al. [91] demonstrated that CaMKI $\gamma$ expression increased the dendrite length of cortical neurons. Consistent with a promoting role in dendrite elaboration RNAi knockdown of CaMKI $\gamma$ decreased dendrite length. The dendrites of cortical neurons from CaMKI $\gamma$ null animals were also attenuated in total length and branch tip number. Previously, CaMKIy had been shown to be important for mediating activity-induced dendrite length in hippocampal neurons [39]. In addition to acting downstream of neuronal activity, RNAi CaMKI $\gamma$ blocked BDNF-induced growth indicating that CaMKI $\gamma$ mediated BDNF effects on dendrite morphology. CaMKIy contains a CAAX sequence, is membrane anchored, and is present in lipid rafts $[73,91]$. Further analysis using DN Rac and STEF (a RacGEF) indicated that CaMKI $\gamma$ mediated a local mechanism to modify dendrite structure upstream of RacGEF STEF and Rac [91].

In addition to the role of Ras-MAPK signaling in mediating activity-induced and basal dendrite elaboration discussed above, Ras can influence dendrite arborization through activation of PI3K and Akt independent of calcium signaling [92]. Rap 1, a GTPase similar to Ras, has also been implicated in regulating dendrite elaboration. Calcium influx via NMDA receptors and L-type VSCCs activated Rap1. Further, Rap1 regulated the activityinduced dendrite complexity of cortical neurons via MAPK- and CREB-mediated signaling [93]. Active Rap1 (Rap1V12) increased dendrite complexity, whereas DN Rap1 (Rap1N17) decreased both basal and activity-induced dendrite complexity. As illustrated by the work of Wayman et al. [39] CaMK and Ras-MAPK kinase path- ways crosstalk with regard to dendrite elaboration. In fact, other studies have demonstrated that Ras-MAPK and AC signaling pathways crosstalk [94]. Identifying these interactions, how they are regulated, and the morphological outcome will continue to be revealed as the field advances.

\section{Activity-Dependent Transcriptional Mechanisms}

Although transcriptional mechanisms have been identified that regulate dendrite morphogenesis [reviewed in 95], few transcriptional mechanisms that regulate dendrite arborization in response to neuronal activity have been identified. Inhibition of new protein synthesis attenuated the activity-induced dendrite growth and suggested a potential contribution of nuclear events in the response [29]. Currently, five transcription factors have been identified that are responsive to neuronal activity and mediators of neuronal morphology. They are CREB, NeuroD, NeuroD2, MEF2, and Sp4.

Studies directed at understanding the signaling mechanisms involved in translating neuronal activity have demonstrated that the transcription factor, CREB is responsive to neuronal activity and calcium signaling. CREB is constitutively bound to DNA and its activation is regulated by phosphorylation at specific residues. The mode of calcium entry plays a significant role in controlling the transcription of genes containing CREB DNA binding sites. For instance, calcium influx via VSCCs was better than calcium influx via NMDA receptors in activating BDNF transcription [96] and c-fos transcription [54, 70]. While calcium influx via VSCCs and NMDA receptors both activated CREB, the kinetics of CREB activation were different. By altering the calcium kinetics after VSCC activation to that of NMDA activation, Hardingham et al. [54] demonstrated that it is the site of calcium entry and not the profile of calcium influx that determines CREB activation kinetics and CRE-mediated transcription.

CREB is activated by phosphorylation by a variety of stimuli and kinases [reviewed in 97]. Phosphorylation of CREB at serine-133 is essential for CREB to activate gene transcription and both CaMK and the MAPK pathways lead to phosphorylation of this site but with different kinetics $[71,98,99]$. Under basal activity conditions pharmacological inhibition of L-type VSCCs suppressed phosphorylation at serine-133 and also attenuated dendrite growth [29]. Inhibiting CREB signaling by expressing the dominant negative KCREB attenuated activity-induced and basal dendrite growth in cortical dissociated neurons 
and slice cultures [29]. Inhibiting CREB by expression of the dominant negative ACREB or siRNA knockdown of CREB attenuated activity-induced dendrite lengthening of 5-9 DIV hippocampal neurons [39]. Inhibiting CREB with dominant negative CREB constructs (KCREB and ACREB) or siRNA has identified CREB as being the mediator of the effect on dendrite elaboration that several kinases elicited including CaMKIV, CaMKI, and MAPK $[29,39]$. These results indicate that CREB plays a key role in activity-induced and basal dendrite growth.

A recently identified substrate of CaMKII is the bHLH transcription factor NeuroD (neurogenic differentiation). Although NeuroD expression did not induce dendrite elaboration, RNAi knockdown of NeuroD decreased both activity-induced and basal dendrite length of cerebellar granule neurons [38]. Introduction of an RNAi-resistant NeuroD rescued dendrite elaboration after RNAi knockdown of NeuroD, whereas phosphorylation site mutants did not. RNAi knockdown of CaMKII $\alpha$ decreased granule cell dendrite arbors and NeuroD phosphorylation. This indicates that phosphorylation is key to NeuroD's role in mediating activity-induced dendrite elaboration. However, phosphorylation of NeuroD did not alter transcription of a heterologous reporter gene. Whether phosphorylation of NeuroD alters transcription of endogenous promoters has not yet been examined.

A second bHLH neurogenic differentiation transcription factor (NeuroD2) has been identified from a screen for calcium responsive genes that activate transcription $[100,101]$. Activity induced NeuroD2 transcriptional activation of the Gap-43 promoter. The specific signaling mechanisms leading to NeuroD2 transcriptional activation was not determined, but was dependent on calcium influx via L-type VSCCs. Interestingly, thalamocortical afferents of NeuroD2 knockout animals failed to segregate into barrels. Although dendrite morphology of layer 4 cortical neurons has not yet been examined, layer 4 cortex cells failed to organize into the walls of the barrels and remained evenly distributed.

MEF2 (myocyte enhancer factor) is another bHLH transcription factor whose transcriptional activity is regulated by neuronal activity $[102,103]$. A role of MEF2 in the differentiation of dendrite claws of cerebellar granule neurons was identified. Shalizi et al. [104] found that phosphorylated MEF2 was also SUMOylated at a neighboring residue and when SUMOylated, MEF2 promoted dendrite claw differentiation. When MEF2 was SUMOylated, however, MEF-specific transcription was attenuated. Activity via L-type VSCCs and NMDA receptors did activate MEF2, but did so by activating the calcium-

Translating Neuronal Activity into Dendrite Elaboration sensitive phosphatase, calcineurin, which dephosphorylated MEF2. After dephosphorylation MEF2 was acetylated instead of SUMOylated. Once acetylated, MEF2 activated transcription. Both neuronal activity and acetylated MEF2 attenuated claw differentiation. Recently, the SUMO E3 ligases mediating MEF2 SUMOylation have been identified. PIAS [protein inhibitors of activated STAT (signal transducer and activator of transcription)] proteins (PIASx) repressed MEF2-dependent transcription and promoted claw differentiation [105]. A similar role for MEF2 in attenuating dendrite differentiation has been reported in the hippocampus. RNAi knockdown of MEF2 increased the number of synapses suggesting that MEF2 normally acts to suppress synapse number [103].

In addition to members of the bHLH family of transcription factors, a Zinc finger transcription factor, Sp4 has recently been shown to mediate activity-induced dendrite development of cerebellar granule neurons [106]. In this system, activity reduced the number of primary dendrites and RNAi knockdown of Sp4 blocked the activity-induced reduction in dendrite number. RNAi Sp4 increased dendrite number and branch points but had no effect on total dendrite length. Expression of Sp4 decreased the number of dendrites and this effect was dependent on the DNAbinding domain. Time lapse imaging of dendrites of neurons with attenuated $\mathrm{Sp} 4$ activity failed to regress, indicating that Sp4 functions to limit branching and regulate pruning during dendrite maturation.

Not only have activity-regulated transcription factors been identified, but components of the transcriptional complex are also sensitive to calcium signaling. CREB binding protein (CBP), calcium-responsive transactivator (CREST), and LIM domain only 4 (LMO4) are three transcriptional coactivators whose transcriptional activity is regulated by calcium signals. The best characterized of these 'transcriptional coactivators' is CBP. CBP binds CREB when CREB is phosphorylated at serine-133. In addition to CBP recruitment to CREB in response to activity, CBP is a substrate of activity-dependent nuclear kinases including CaMKIV and Rsk2, which regulate it's activity. In cortical neurons inhibition of CBP produced a greater attenuation of dendrite growth than CREB inhibition [29]. This suggests that morphological increases in dendrite complexity are mediated via CREB/CBP and not via CREB recruitment of a different transcriptional coactivator. It also suggests that other calcium-sensitive transcriptional mechanisms utilize CBP. In fact, the recently identified protein CREST binds CBP [101].

CREST was identified from a 'transactivator trap' screen to identify calcium-activated transcription factors 
[101]. CREST activated transcription in response to calcium influx via L-type VSCCs and NMDA receptors. CREST is enriched in the early postnatal cortex coincident with the time of maximal dendrite elaboration. This developmental regulation suggests that it may contribute to dendrite growth. To determine whether CREST was necessary for dendrite growth, Aizawa et al. [101] generated CREST null animals and examined the morphology of pyramidal neurons. Cortical layer 5 pyramidal neurons showed dramatically decreased basal dendrite length and number of branch points. Basal dendrites were approximately $70 \%$ shorter than in control animals and dendrites $50 \%$ less branched. Hippocampal neurons in CREST null animals also showed a dramatic reduction in dendrite complexity. In addition, CREST null neurons in vitro did not induce dendrite arborization in response to activity. The inability of CREST null neurons to respond was rescued by the expression of CREST in the null neurons.

Another gene identified from the transactivator trap screen, LIM domain only 4 (LMO4), activates transcription in response to calcium influx via L-type VSCCs, glutamate receptors, and synaptic activity [101, 107]. CaMKIV and PKA activated LMO4-mediated transcription. Although active MEK was not sufficient to activate LMO4 transcriptional activity, inhibiting MEKattenuated LMO4, suggesting that MEK signaling may also be involved in LMO4 activation. LMO4 does not contain DNA binding motifs but binds CREB and cofactor of LIM homeodomain protein (CLIM), another transcriptional coactivator. Although not examined, evidence from the somatosensory cortex of LMO4 knockout animals hints that LMO4 may function in dendrite arborization. Thalamocortical afferents in LMO4 knockout animals failed to segregate into barrels and layer 4 cortical neurons did not organize into the walls of the barrels. No gross defects in the dendrites of layer $2 / 3$ pyramidal neurons were detected in LMO4 knockout animals, but careful analysis is needed.

Interestingly, the C-terminal fragment of the L-type VSCC (Cav1.2) translocates to neuronal nuclei as CCAT (calcium channel-associated transcription regulator). In a heterologous reporter system, CCAT activated gene transcription independent of DNA binding [108]. Neuronal activity decreased nuclear CCAT, suggesting that CCAT export is regulated by activity. When expressed in cerebellar granule neurons CCAT increased the number of primary dendrites and their length. Identifying the transcriptional targets of CCAT will be of interest in determining whether CCAT acts to activate or repress effectors of dendrite complexity.

\section{Transcriptionally Regulated Effectors of Dendrite Complexity}

A wide range of putative molecular effectors of neuronal activity has been identified including transcription factors and proteins involved in regulating the structure and function of synapses $[109,110]$. Considering the central role of CREB in mediating activity-dependent gene transcription and changes in dendrite elaboration, identifying CREB target genes would seem to be a feasible approach to identifying the downstream effectors. However, genome-wide analysis of CREB binding motifs yielded 1,349 sites in the mouse and 1,663 in the human genome [111]. Further analyses and additional screens have indicated that CREB occupies approximately 4,000-6,000 promoter sites $[112,113]$. It will take some time before all these potential targets are validated and their role in neurons identified.

One gene shown to be regulated by activity via calcium activation of CREB-mediated signaling is brain-derived neurotrophic factor (BDNF) $[96,114-117]$. BDNF has been extensively studied and there is considerable in vitro and in vivo evidence that it mediates dendrite elaboration. Neurons in vitro when exposed to BDNF increased their dendrite complexity [118-120]. Expression of BDNF in in vitro slice cultures increased primary dendrites of both ferret and rat pyramidal neurons [119-121]. Most studies demonstrating that BDNF induces dendrite elaboration either apply BDNF in the medium or overexpress BDNF in neurons. Horch and Katz [122] asked the question whether BDNF's ability to alter dendrite arborization was spatially limited. Using cortical slice cultures from P27 ferrets, BDNF was expressed in cortical neurons and the dendrites of neighboring neurons were analyzed. They found that dendrites from neighboring neurons showed greater complexity in a distance-dependent manner. Dendrites that were within $4.5 \mu \mathrm{m}$ of the BDNFexpressing neuron were more complex. The results from this study indicated that BDNF-induced dendrite branching is spatially restricted [122].

BDNF's role in dendrite elaboration is not limited to pyramidal neurons but also mediates basal and induced dendrite growth of interneurons [121, 123]. Jin et al. [123] used blocking BDNF antibodies and pharmacological blockade of the BDNF receptor, TrkB, to remove BDNF signaling in slice cultures. In these conditions, GAD67 expressing neurons had less extensive dendrite arbors. The GAD67 promoter was used to express BDNF selectively in GABAergic interneurons in vitro. GABAergic interneurons that expressed BDNF had longer and more 
branched dendrites, indicating that BDNF can promote dendrite complexity of interneurons.

BDNF, however, is not a general mechanism to induce dendrite elaboration, but displays neuron-specific and temporal selectivity in its action. Exposure of cortical slice cultures to BDNF resulted in laminar-specific effects on dendrite complexity. BDNF had the most pronounced effect promoting complexity of basal and apical dendrites of layer 4 pyramidal neurons and some effect on layer 5 apical and basal dendrites [119]. However, BDNF did not promote dendrite complexity of layer 6 pyramidal neurons, and in fact may have attenuated dendrite complexity. In a separate study, BDNF increased the complexity of layer 5 , but not layer $2 / 3$ pyramidal neurons [121]. While layer 6 pyramidal neurons in the ferret showed no increase in complexity in response to BDNF, rat layer 6 pyramidal neurons were more complex after BDNF exposure, indicating that there may also be some species or temporal regulation of BDNF responsiveness $[119,121]$.

Other neurotrophins have been shown to promote dendrite elaboration of cortical pyramidal neurons in a laminar-specific manner [119]. Whereas BDNF did not significantly alter layer 6 pyramidal dendrites in the ferret, neurotrophin-4 (NT-4) promoted basal and apical dendrite complexity. NT-4 also dramatically increased layer 5 basal but not apical dendrites. Neurotrophin-3 (NT-3), however, only slightly increased the complexity of layer 6 pyramidal neurons and had little effect on layer 5 or layer 4 pyramidal neurons. In the rat NT- 4 also increased the dendrite complexity of layer 6 pyramidal neurons, as well as layer $2 / 3$ pyramidal dendrites [121]. Interestingly, the difference in NT-3 and BDNF effects on pyramidal neuron layer 4 and layer 6 dendrites has been attributed to antagonistic actions of NT-3 and BDNF. Using Trk receptor bodies McAllister et al. [124] demonstrated that NT-3 inhibited BDNF-stimulated growth of layer 4 pyramidal basal dendrites and BNDF inhibited NT-3-stimulated growth of layer 6 pyramidal basal dendrites.

Evidence from studies of BDNF null mice indicates that BDNF may also be critical for the maintenance of dendrites. Gorski et al. [125] showed that in BDNF conditional null animals dendrite arbors of layer $2 / 3$ cortical pyramidal neurons at postnatal day 14 were not different from those of control animals. However, at postnatal day 21 the number of primary dendrites was less in the null animals. By postnatal day 35, there was a greater disparity in the number of primary dendrites between null and control animals. Branching as well as dendrite extent (as measured by Sholl analysis) was also attenuated in BDNF null animals [125]. In addition, in TrkB conditional null animals the dendrite arbors of cortical layer $2 / 3$ pyramidal neurons were dramatically attenuated at postnatal day 42. Although the number of primary dendrites was not different between control and null animals, there was a significant reduction in the number and length of dendrite branches [126].

Surface expression of TrkB, the receptor for BDNF, is regulated by neuronal activity at multiple levels including increased insertion into the plasma membrane [127], enhanced endocytosis of BDNF-TrkB signaling complex, and activation of transcription of the TrkB gene [reviewed in 128]. Activation of TrkB gene expression in cortical neurons is dependent on VSCCs [129]. Neuronal activity also increased kinase activity [127]. The role of TrkB in mediating dendrite growth is complicated by the fact that in addition to the full length TrkB protein, truncated versions ( $\mathrm{T} 1$ and $\mathrm{T} 2$ ) that lack the intracellular kinase domain are transcribed. A comparative analysis of fulllength and truncated TrkB revealed that TrkB regulated the mode of dendrite growth [130]. Specifically, fulllength TrkB increased the number of branches and created a proximal dendrite 'halo' but without altering total dendrite length. On the other hand, truncated TrkB (T1) increased total dendrite length by addition to distal dendrites, but had not effect on the number of branches.

The expression of candidate plasticity gene-15 (cpg15/ neuritin) is also regulated by activity [131]. Activity-dependent transcription of the cpg 15 gene is induced by calcium influx via L-type VSCCs and NMDA receptors and mediated in part by CREB [132]. Cpg15 expression is modulated in the somatosensory cortex in parallel with changes in sensory experience and reduced in CREB null animals [133]. In Xenopus tectal neurons cpg15 enhanced total dendrite arbor growth by increasing branch length [109] and promoted neuritogenesis of hippocampal and cortical neurons in vitro [134].

The secreted protein, Wnt-2 was identified in a serial analysis of chromatin occupancy (SACO) screen as a potential CREB-regulated gene containing a CRE element. After depolarization of hippocampal neurons, Wnt-2 expression increased dependent upon CREB signaling [39]. When expressed in hippocampal neurons Wnt-2 induced increase in total dendrite length, indicating that Wnt-2 was sufficient to induce an increase in dendrite complexity. Inhibiting Wnt signaling with Wif, a secreted protein that binds Wnt and prevents interaction with the Wnt receptor frizzled, blocked Wnt-2 induced dendrite growth. Wif also blocked activity-induced dendrite 


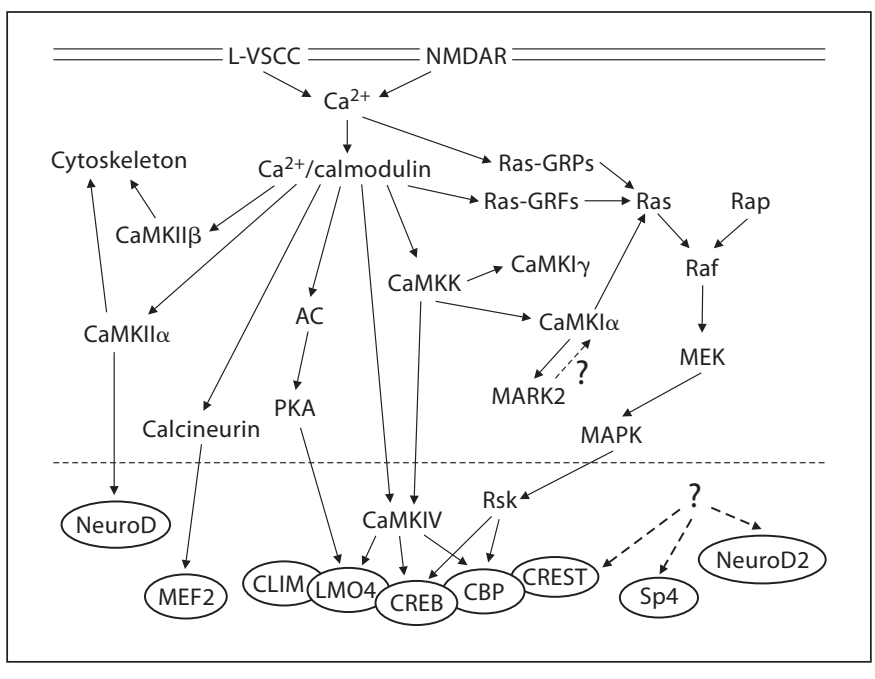

Fig. 1. Model of neuronal activity-induced calcium signaling in neurons. L-type voltage-sensitive calcium channels (L-VSCC) and N-methyl-D-aspartate receptors (NMDAR) open allowing $\mathrm{Ca}^{2+}$ entry. Once in the cytoplasm, $\mathrm{Ca}^{2+}$ binds calmodulin. $\mathrm{Ca}^{2+} /$ calmodulin activates a number of cytoplasmic proteins including $\mathrm{Ca}^{2+} /$ calmodulin-dependent protein kinases (CaMK), Ras-guanine-nucleotide-releasing factors (Ras-GRFs), and adenylyl cyclases (AC). Some of these kinases, such as CaMKII $\alpha$ and CaMKII $\beta$, act locally to alter the cytoskeleton. Others, such as CaMK kinase (CaMKK), CaMKI $\alpha$, and Ras-GRFs, activate additional signaling proteins in the cytoplasm and nucleus (dashed line). Calcium-sensitive nuclear transcription factors, including cAMP-responsive element-binding protein (CREB), neurogenic differentiation (NeuroD), NeuroD2, myocyte enhancer factor 2 (MEF2) and Sp4 regulate gene transcription. In addition to transcription factors, proteins that bind transcription factors including Calcium-responsive transactivator (CREST), CREB-binding protein (CBP), and LIM domain only 4 (LMO4) are also activated in response to calcium signaling. How calcium induces activation of CREST, Sp4, and NeuroD2 is not yet know. CLIM = Cofactor of LIM homeodomain protein; MARK2 = microtubule affinityregulating kinase 2 ; MAPK $=$ mitogen-activated protein kinase; $\mathrm{MEK}=\mathrm{MAPK} / \mathrm{ERK}$ kinase; $\mathrm{PKA}=$ protein kinase $\mathrm{A}$; RasGRPs = Ras-guanine-nucleotide-releasing proteins

growth. This suggests that Wnt-2 was primarily responsible for mediating dendrite growth [39]. Yu and Malenka [37] also reported that Wnt release was increased in hippocampal neurons after neuronal activity was increased. In this study, $\beta$-catenin was identified as the downstream effector of Wnt. Expression of $\beta$-catenin in hippocampal neurons dramatically increased dendrite complexity in a dose-dependent manner. Attenuation of $\beta$-catenin with sequestration by expression of intracellular domain of $\mathrm{N}$ cadherin (Ncad-intra) attenuated basal dendrite elaboration and blocked $\beta$-catenin-mediated growth. Ncad-intra also blocked activity-induced dendrite elaboration. Although the magnitude of the effect was reduced with age, $\beta$-catenin also induced dendrite elaboration in older hippocampal neurons and promoted dendrite spine formation [135].

A new and exciting mechanism for activity-induced regulation of dendrite arborization has been the identification of two microRNAs that act to modify dendrite complexity. Vo et al. [136] identified miRNA-132 as a CREB target. miRNA-132 was highly induced by neurotrophins and its expression induced neurite growth via p250GAP signaling. The second miRNA, miRNA-134, was found to regulate dendrite spine development through the inhibition of LimK1 [137]. Interestingly, BDNF was found to relieve miR-134 inhibition of LimK1. Although not transcriptionally produced in response to neuronal activity, Rho GTPases clearly play a role in mediating dendrite elaboration in response to activity via local signaling mechanisms and have been reviewed elsewhere $[35,138]$.

\section{Conclusion}

From the early Golgi studies to more sophisticated imaging studies, it is clear that neuronal activity has profound effects on neuronal connectivity and dendrite complexity. The intracellular proteins that translate neuronal activity into morphological changes are numerous and range from proteins that act in the dendrite to those that recruit nuclear signaling and regulate gene transcription (fig. 1). The individual contribution of each of these components is only beginning to be understood. With the ongoing identification of genes that are induced by neuronal activity and identification of their role in dendrite elaboration elucidated, the magnitude of options a neuron has for decoding neuronal activity escalates. In light of the numerous components of dendrite arborization, this plethora of possibilities allows exquisite control for promoting and limiting dendrite initiation, branching, elongation, and spine formation. How the activation and regulation of these molecules is coordinated to elicit specific changes in dendrite complexity via the regulation of a certain set of genes are intricate secrets yet to be divulged by neurons.

\section{Acknowledgement}

I apologize to numerous authors whose papers could not be cited due to space limitations. 


\section{References}

$\checkmark 1$ Gilbert CD: Microcircuitry of the visual cortex. Annu Rev Neurosci 1983;6:217-247.

-2 Hausser M, Spruston N, Stuart GJ: Diversity and dynamics of dendritic signaling. Science 2000;290:739-744.

- 3 Segev I, London M: Untangling dendrites with quantitative models. Science 2000;290: 744-750.

$\checkmark 4$ O'Leary DDM, Koester SE: Development of projection neuron types, axon pathways, and patterned connections of the mammalian cortex. Neuron 1993;10:991-1006.

$\checkmark 5$ Scott EK, Luo L: How do dendrites take their shape? Nat Neurosci 2001;4:359-365.

6 Bradke F, Dotti CG: Establishment of neuronal polarity: lessons from cultured hippocampal neurons. Curr Opin Neurobiol 2000; 10:574-581.

7 Polleux F, Morrow T, Ghosh A: Semaphorin $3 \mathrm{~A}$ is a chemoattractant for cortical apical dendrites. Nature 2000;404:567-573.

$\checkmark 8$ Miller M: Maturation of rat visual cortex. I. A quantitative study of Golgi-impregnated pyramidal neurons. J Neurocyt 1981;10:859878.

-9 Miller MW: Maturation of rat visual cortex. III. Postnatal morphogenesis and synaptogenesis of local circuit neurons. Brain Res Dev Brain Res 1986;25:271-285.

10 Miller M, Peters A: Maturation of rat visual cortex. II. A combined Golgi-electron microscope study of pyramidal neurons. J Comp Neurol 1981;203:555-573.

-11 Wise SP, Fleshman JW Jr, Jones EG: Maturation of pyramidal cell form in relation to developing afferent and efferent connections of rat somatic sensory cortex. Neuroscience 1979;4:1275-1297.

12 Purpura DP: Dendritic differentiation in human cerebral cortex: normal and aberrant developmental patterns. Adv Neurol 1975; 12:91-116.

13 Fiala JC, Feinberg M, Popov V, Harris KM: Synaptogenesis via dendritic filopodia in developing hippocampal area CA1. J Neurosci 1998;18:8900-8911.

14 Dailey ME, Smith SJ: The dynamics of dendritic structure in developing hippocampal slices. J Neurosci 1996;16:2983-2994.

15 Greenough WT, Chang FL: Dendritic pattern formation involves both oriented regression and oriented growth in barrels of mouse somatosensory cortex. Brain Res 1988;471:148-152.

16 Malun D, Brunjes PC: Development of olfactory glomeruli: temporal and spatial interactions between olfactory receptor axons and mitral cells in opossums and rats. J Comp Neurol 1996;368:1-16.
17 Verhage M, Maia AS, Plomp JJ, Brussaard $\mathrm{AB}$, Heeroma JH, Vermeer $\mathrm{H}$, Toonen RF, Hammer RE, van der Berg TK, Missler M, Geuze HJ, Sudhol TC: Synaptic assembly of the brain in the absence of neurotransmitter secretion. Science 2000;287:864-869.

18 Crowley JC, Katz LC: Early development of ocular dominance columns. Science 2000; 290:1321-1324.

19 Wu GY, Malinow R, Cline HT: Maturation of a central glutamergic synapse. Science 1996; 274:972-976.

$20 \mathrm{Wu}$ GY, Zou DJ, Rajan I, Cline HT: Dendritic dynamics in vivo change during neuronal maturation. J Neurosci 1999;19:4427-4483.

21 Rajan I, Cline HT: Glutamate receptor activity is required for normal development of tectal cell dendrites in vivo. J Neurosci 1998; 18:7836-7846.

22 Coleman PD, Riesen AH: Environmental effects on cortical dendritic fields. I. Rearing in the dark. J Anat 1968;102:363-374.

23 Wiesel TN, Hubel DH: Effects of visual deprivation on morphology and physiology of cells in the cat's lateral geniculate body. J Neurophysiol 1963;26:978-993.

24 Harris RM, Woolsey TA: Morphology of Golgi-impregnated neurons in mouse cortical barrels following vibrissae damage at different postnatal ages. Brain Res 1979;161: 143-149.

-25 Steffen H, Van der Loos H: Early lesions of mouse vibrissal follicles: their influence on dendritic orientation in the cortical barrelfield. Exp Brain Res 1980;40:410-431.

26 Inglis FM, Zuckerman KE, Kalb RG: Experience-dependent development of spinal motor neurons. Neuron 2000;26:299-305.

27 Rakic P: Role of cell interaction in development of dendritic patterns. Adv Neurol 1975; 12:117-134.

28 Altman J, Anderson WJ: Experimental reorganization of the cerebellar cortex. I. Morphological effects of elimination of all microneurons with prolonged X-irradiation started at birth. J Comp Neurol 1972;146: 355-406.

29 Redmond L, Kashani AH, Ghosh A: Calcium regulation of dendritic growth via CaM kinase IV and CREB-mediated transcription. Neuron 2002;34:999-1010.

30 Engert F, Bonhoeffer T: Dendritic spine changes associated with hippocampal longterm synaptic plasticity. Nature 1999;399: 66-70.

-31 Maletic-Savatic M, Malinow R, Svoboda K: Rapid dendritic morphogenesis in CAl hippocampal dendrites induced by synaptic activity. Science 1999;283:1923-1927.

32 Holloway RL: Dendritic branching: some preliminary results of training and complexity in rat visual cortex. Brain Res 1966;2:393396.
-33 Greenough WT, Volkmar FR: Pattern of dendritic branching in occipital cortex of rats reared in complex environments. Exp Neurol 1973;40:491-504

-34 Volkmar FR, Greenough WT: Rearing complexity affects branching of dendrites in the visual cortex of the rat. Science 1972;176: 1145-1147.

35 Sin WC, Haas K, Ruthazer ES, Cline HT: Dendrite growth increased by visual activity requires NMDA receptor and Rho GTPases. Nature 2002;419:475-480.

36 Vaillant AR, Zanassi P, Walsh GS, Aumont A, Alonso A, Miller FD: Signaling mechanisms underlying reversible, activity-dependent dendrite formation. Neuron 2002;34: 985-998.

- 37 Yu X, Malenka RC: Beta-catenin is critical for dendritic morphogenesis. Nat Neurosci 2003;6:1169-1177.

38 Gaudilliere B, Konishi Y, de la Iglesia N, Yao G, Bonni A: A CaMKII-NeuroD signaling pathway specifies dendritic morphogenesis. Neuron 2004;41:229-241.

39 Wayman GA, Impey S, Marks D, Saneyoshi T, Grant WF, Derkach V, Soderling TR: Activity-dependent dendritic arborization mediated by CaM-kinase I activation and enhanced CREB-dependent transcription of Wnt-2. Neuron 2006;50:897-909.

40 Rakic P, Sidman RL: Organization of cerebellar cortex secondary to deficit of granule cells in weaver mutant mice. J Comp Neurol 1973;152:133-161.

41 Sotelo C: Anatomical, physiological and biochemical studies of the cerebellum from mutant mice. II. Morphological study of cerebellar cortical neurons and circuits in the weaver mouse. Brain Res 1975;94:19-44.

-42 Mason CA, Morrison ME, Ward MS, Zhang Q, Baird DH: Axon-target interactions in the developing cerebellum. Perspect Dev Neurobiol 1997;5:69-82.

43 Benes FM, Parks TN, Rubel EW: Rapid dendritic atrophy following deafferentation: an EM morphometric analysis. Brain Res 1977; 122:1-13.

44 Deitch JS, Rubel EW: Afferent influences in brain stem auditory nuclei of the chicken: time course and specificity of dendritic atrophy following deafferentation. J Comp Neurol 1984;229:66-79.

45 Purves D, Hume RI: The relation of postsynaptic geometry to the number of presynaptic axons that innervate autonomic ganglion cells. J Neurosci 1981;1:441-452.

46 Kalb RG: Regulation of motor neuron dendrite growth by NMDA receptor activation. Development 1994;120:3063-3071.

47 Ivanco TL, Racine RJ, Kolb B: Morphology of layer III pyramidal neurons is altered following induction of LTP in sensorimotor cortex of the freely moving rat. Synapse 2000;37: $16-22$. 
-48 Bartsch D, Ghirardi M, Skehel PA, Karl KA, Herder SP, Chen M, Bailey CH, Kandel ER: Aplysia CREB2 represses long-term facilitation: relief of repression converts transient facilitation into long-term functional and structural change. Cell 1995;83:979-992.

-49 Kozorovitskiy Y, Gross CG, Kopil C, Battaglia, L, McBreen M, Stranahan AM, Gould E: Experience induces structural and biochemical changes in the adult primate brain. Proc Natl Acad Sci USA 2005;102:17478-17482.

50 Hille B: Ion Channels of Excitable Membranes, ed 3. Sunderland, Sinauer Associates, 2001.

-51 Lohmann C, Wong ROL: Regulation of dendritic growth and plasticity by local and global calcium dynamics. Cell Calcium 2005;47:403-409.

52 Lohmann C, Finski A, Bonhoeffer T: Local calcium transients regulate the spontaneous motility of dendritic filopodia. Nat Neurosci 2005;8:305-312.

53 Ghosh A, Greenberg ME: Calcium signaling in neurons: molecular mechanisms and cellular consequences. Science 1995;268:239247.

54 Hardingham GE, Chawla S, Cruzalegui FH, Bading H: Control of recruitment and transcription-activating function of CBP determines gene regulation by NMDA receptors and L-type calcium channels. Neuron 1999; 22:789-798.

55 West AE, Griffith EC, Greenberg ME: Regulation of transcription factors by neuronal activity. Nat Rev Neurosci 2002;3:921-931.

56 Sheng M, Hoogenraad CC: The postsynaptic architecture of excitatory synapses: a more quantitative view. Annu Rev Biochem 2007; 76:823-847.

57 Jakowec MW, Fox AJ, Martin LJ, Kalb RG: Quantitative and qualitative changes in AMPA receptor expression during spinal cord development. Neuroscience 1995;67: 893-907.

58 Inglis FM, Crockett R, Korada S, Abraham, WC, Hollmann M, Kalb RG: The AMPA receptor subunit GluR1 regulates dendritic architecture of motor neurons. J Neurosci 2002;22:8042-8052.

-59 Iwasato T, Datwani A, Wolf AM, Nishiyama H, Taguchi Y, Tonegawa S, Knöpfel T, Erzurumlu RS, Itohara S: Cortex-restricted disruption of NMDAR1 impairs neuronal patterns in the barrel cortex. Nature 2000; 406:726-731.

-60 Datwani A, Iwasato T, Itohara S, Erzurumlu RS: NMDA receptor-dependent pattern transfer from afferents to postsynaptic cells and dendritic differentiation in the Barrel cortex. Mol Cell Neurosci 2002;21:477-492.

61 Tyndall SJ, Patel SJ, Walikonis RS: Hepatocyte growth factor-induced enhancement of dendritic branching is blocked by inhibitors of N-methyl-D-aspartate receptors and calcium/calmodulin-dependent kinases. J Neurosci Res 2007;85:2343-2351.
62 Borodinsky LN, O'Leary DO, Neale JH, Vicini S, Coso OA, Fiszman ML: GABA-induced neurite outgrowth of cerebellar granule cells is mediated by GABAA receptor activation, calcium influx and CaMKII and erk1/2 pathways. J Neurochem 2003;84: 1411-1420.

-63 Kobayashi T, Yamada Y, Fukao M, Tsutsuura M, Tohse N: Regulation of Cav1.2 current: Interaction with intracellular molecules. J Pharmacol Sci 2007; 103:347-353.

64 Burgoyne RD: Neuronal calcium sensor proteins: generating diversity in neuronal $\mathrm{Ca}^{2+}$ signaling. Nat Rev Neurosci 2007;8:182193.

65 Hardingham GE, Arnold FJ, Bading H: Nuclear calcium signaling controls CREB-mediated gene expression triggered by synaptic activity. Nat Neurosci 2001;4:261-267.

66 Hardingham GE, Chawla S, Johnson CM, Bading $\mathrm{H}$ : Distinct functions of nuclear and cytoplasmic calcium in the control of gene expression. Nature 1997;385:260-265.

67 Ehlers MD, Zhang S, Bernhadt JP, Huganir RL: Inactivation of NMDA receptors by direct interaction of calmodulin with the NR1 subunit. Cell 1996;84:745-755.

68 Dolmetsch RE, Pajvani U, Fife K, Spotts JM, Greenberg ME: Signaling to the nucleus by an L-type calcium channel-calmodulin complex through the MAP kinase pathway. Science 2001;294:333-339.

69 Fink CC, Bayer KU, Myers JW, Ferrell JE Jr, Schulman H, Meyer T: Selective regulation of neurite extension and synapse formation by the beta but not the alpha isoform of CaMKII. Neuron 2003;39:283-297.

70 Bading H, Ginty DD, Greenberg ME: Regulation of gene expression in hippocampal neurons by distinct calcium signaling pathways. Science 1993;260:181-186.

71 Hook SS, Means AR: $\mathrm{Ca}^{2+} / \mathrm{CaM}$-dependent kinases: from activation to function. Annu Rev Pharmacol Toxicol 2001;41:471-505.

72 Soderling TR: The $\mathrm{Ca}^{2+}$-calmodulin-dependent protein kinase cascade TIBS 1999;24: 232-236.

73 Takemoto-Kimura S, Terai H, Takamoto M Ohmae S, Kikumura S, Segi E, Arakawa Y, Furuyashiki T, Narumiya S, Bito H: Molecular cloning and characterization of CLICKIII/CaMKI $\gamma$, a novel membrane-anchored neuronal $\mathrm{Ca}^{2+} /$ calmodulin-dependent protein kinase (CaMK). J Biol Chem 2003;278: 18597-18605.

74 Rosen LB, Ginty DD, Weber MJ, Greenberg ME: Membrane depolarization and calcium influx stimulate MEK and MAP kinase via activation of Ras. Neuron 1994;12:12071221.

75 Cullen PJ, Lockyer PJ: Integration of calcium and ras signaling. Nat Rev Mol Cell Biol 2002;3:339-348

76 Ferguson GD, Storm DR: Why calciumstimulated adenylyl cyclases? Physiology (Bethesda) 2004;19:271-276.
77 Abdel-Majid RM, Leong WL, Schalkwyk LC, Smallman DS, Wong ST, Storm DR, Fine A, Dobson MJ, Guernsey DL, Neumann PE: Loss of adenylyl cyclase I activity disrupts patterning of mouse somatosensory cortex. Nat Genet 1998;19:289-291.

78 Welker E, Armstrong-James M, Bronchti G, Ourednik W, Gheorghita-Baechler F, Dubois R, Guernsey DL, Van der Loos H, Neumann PE: Altered sensory processing in the somatosensory cortex of the mouse mutant barrelless. Science 1996;271:1864-1867.

79 Westenbroek RE, Ahlijanian MK, Catterall WA: Clustering of L-type $\mathrm{Ca}^{2+}$ channels at the base of major dendrites in hippocampal pyramidal neurons. Nature 1990;347:281284.

$>80$ Hardingham GE, Arnold FJL, Bading H: A calcium microdomain near NMDA receptors: on switch for ERK-dependent synapseto-nucleus communication. Nat Neurosci 2001;4:565-566.

$>81$ Lisman J, Schulman H, Cline H: The molecular basis of CaMKII function in synaptic and behavioural memory. Nat Rev Neurosci 2002;3:175-190.

$>82$ Wu GY, Cline HT: Stabilization of dendritic arbor structure in vivo by CaMKII. Science 1998;279:222-226.

83 Zou DJ, Cline HT: Postsynaptic calcium/ calmodulin-dependent protein kinase II is required to limit elaboration of presynaptic and postsynaptic neuronal arbors. J Neurosci 1999;19:8909-8918.

-84 Jensen KF, Ohmstede CA, Fisher RS, Sahyoun $\mathrm{N}$ : Nuclear and axonal localization of $\mathrm{Ca}^{2+} /$ calmodulin-dependent protein kinase type Gr in rat cerebellar cortex. Proc Natl Acad Sci USA 1991;88:2850-2853.

85 Wayman GA, Kaech S, Grant WF, Davare M, Impey S, Tokumitsu H, Nazaki N, Banker G, Soderling TR: Regulation of axonal extension and growth cone motility by calmodulin-dependent protein kinase I. J Neurosci 2004;24:3786-3794.

86 Kamata A, Sakagami H, Tokumitsu H, Sanda M, Owada Y, Fukunaga K, Kondo H: Distinct developmental expression of two isoforms of $\mathrm{Ca}^{2+} /$ calmodulin-dependent protein kinase kinases and their involvement in hippocampal dendritic formation. Neurosci Lett 2007;423:143-148.

87 Schmitt JM, Wayman GA, Nozaki N, Soderling TR: Calcium activation of ERK mediated by calmodulin kinase I. J Biol Chem 2004; 279:24064-24072.

88 Picciotto MR, Zoli M, Bertuzzi G, Nairn AC: Immunochemical localization of calcium/ calmodulin-dependent protein kinase I. Synapse 1995;20:75-84.

89 Stedman DR, Uboha NV, Stedman TT, Nairn AC, Picciotto MR: Cytoplasmic localization of calcium/calmodulin-dependent protein kinase I-alpha depends on a nuclear export signal in its regulatory domain. FEBS Lett 2004;566:275-280. 
\$0 Uboha NV, Flajolet M, Nairn AC, Picciotto MR: A calcium- and calmodulin-dependent kinase $\mathrm{I} \alpha /$ microtubule affinity regulating kinase 2 signaling cascade mediates calcium-dependent neurite outgrowth. J Neurosci 2007;27:4413-4423.

-91 Takemoto-Kimura S, Ageta-Ishihara N, Nonaka M, Adachi-Morishima A, Mano T, Okamura M, Fujii H, Fuse T, Hoshino M, Suzuki S, Kojima M, Mishina M, Okuno H, Bito $\mathrm{H}$ : Regulation of dendritogenesis via a lipid-raft-associated $\mathrm{Ca}^{2+} /$ calmodulin-dependent protein kinase CLICK-III/CaMKI $\gamma$. Neuron 2007;54:755-770.

-92 Kumar V, Zhang M-X, Swank, MW, Kunz J, Wu G-Y: Regulation of dendritic morphogenesis by Ras-PI3K-Akt-mTOR and RasMAPK signaling pathways. J Neurosci 2005;25:11288-11299.

93 Chen Y, Wang PY, Ghosh A: Regulation of cortical dendrite development by Rap1 signaling. Mol Cell Neurosci 2005;28:215228.

-94 Impey S, Obrietan K, Wong ST, Poser S, Yano S, Wayman G, Deloulme JC, Chan G, Storm DR: Cross talk between ERK and PKA is required for $\mathrm{Ca}^{2+}$ stimulation of CREB-dependent transcription and ERK nuclear translocation. Neuron 1998;21: 869-883.

$\checkmark 95$ Parrish JZ, Emoto K, Kim MD, Jan YN: Mechanisms that regulate establishment, maintenance, and remodeling of dendritic fields. Annu Rev Neurosci 2007;30:399423.

96 Ghosh A, Carnahan J, Greenberg ME: Requirement for BDNF in activity-dependent survival of cortical neurons. Science 1994; 263:1618-1623.

$\checkmark 97$ Johannessen M, Delghandi MP, Moens U: What turns CREB on? Cell Signalling 2004; 16:1211-1227.

98 Wu GY, Diesseroth K, Tsien RW: Activitydependent CREB phosphorylation: Convergence of a fast, sensitive calmodulin $\mathrm{ki}$ nase pathway and a slow, less sensitive mitogen-activated protein kinase pathway. Proc Natl Acad Sci USA 2001;98:28022813.

$\checkmark 99$ Enslen H, Sun P, Brickey D, Soderling SH, Klamo E, Soderling TR: Characterization of $\mathrm{Ca}^{2+} /$ calmodulin-dependent protein $\mathrm{ki}$ nase IV. Role in transcriptional regulation. J Biol Chem 1994;269:15520-15527.

- 100 Ince-Dunn G, Hall BJ, Hu SC, Ripley B, Huganir RL, Olson JM, Tapscott SJ, Ghosh A: Regulation of thalamocortical patterning and synaptic maturation by NeuroD2. Neuron 2006;49:683-695.

- 101 Aizawa H, Hu SC, Bobb K, Balakrishnan K, Ince G, Gurevich I, Cowan M, Ghosh A: Dendrite development regulated by CREST, a calcium-regulated transcriptional activator. Science 2004;303:197-202
102 Mao Z, Bonni A, Xia F, Nadal-Vicens M, Greenberg ME: Neuronal activity-dependent cell survival mediated by transcription factor MEF2. Science 1999;286:785790.

103 Flavell SW, Cowan CW, Kim TK, Greer PL, Lin Y, Paradis S, Griffith EC, Hu LS, Chen C, Greenberg ME: Activity-dependent regulation of MEF2 transcription factors suppresses excitatory synapse number. Science 2006;311:1008-1012.

104 Shalizi A, Gaudilliere B, Yuan Z, Stegmuller J, Shirogane T, Ge Q, Tan Y, Schulman B, Harper JW, Bonni A: A calcium-regulated MEF2 sumoylation switch controls postsynaptic differentiation. Science 2006;311: 1012-1007.

105 Shalizi A, Bilimoria PM, Stegmuller J, Gaudilliere B, Yang Y, Shuai K, Bonni A: PIASx is a MEF2 SUMO E3 ligase that promotes postsynaptic dendritic morphogenesis. J Neurosci 2007;27:10037-10046.

106 Ramos B, Gaudilliere B, Bonni A, Gill G: Transcription factor $\mathrm{Sp} 4$ regulates dendritic patterning during cerebellar maturation. Proc Natl Acad Sci USA 2007;104:98829887.

107 Kashani AH, Qiu Z, Jurata L, Lee SK, Pfaff S, Goebbels S, Nave KA, Ghosh A: Calcium activation of the LMO4 transcription complex and its role in the patterning of thalamocortical connections. J Neurosci 2006; 26:8398-8408.

108 Gomez-Ospina N, Tsuruta F, BarretoChang O, Hu L, Dolmetsch R: The C terminus of the L-type voltage-gated calcium channel $\mathrm{Ca}(\mathrm{V}) 1.2$ encodes a transcription factor. Cell 2006;127:591-606

109 Nedivi E: Molecular analysis of developmental plasticity in neocortex. J Neurobiol 1999;41:135-147.

110 Sheng M, Kim MJ: Postsynaptic signaling and plasticity mechanisms. Science 2002; 298:776-780

111 Conkright MD, Guzman E, Flechner L, Su AI, Hogenesch JB, Montminy M: Genomewide analysis of CREB target genes reveals a core promoter requirement for cAMP responsiveness. Mol Cell 2003;11:1101-1108.

112 Zhang X, Odom DT, Koo SH, Conkright MD, Canettieri G, Best J, Chen H, Jenner R, Herbolsheimer E, Jacobsen E, Kadam S, Ecker JR, Emerson B, Hogenesch JB, Unterman T, Young RA, Montminy M: Genomewide analysis of cAMP-response element binding protein occupancy, phosphorylation, and target gene activation in human tissues. Proc Natl Acad Sci USA 2005;102: 4459-4464.

113 Impey S, McCorkle SR, Cha-Molstad H, Dwyer JM, Yochum GS, Boss JM, McWeeney S, Dunn JJ, Mandel G, Goodman RH: Defining the CREB regulon: a genomewide analysis of transcription factor regulatory regions. Cell 2004;119:1041-1054.
114 Shieh PB, Hu S-C, Bobb K, Timmusk T, Ghosh A: Identification of a signaling pathway involved in calcium regulation of BDNF expression. Neuron 1998;20:727740.

115 Tao X, Finkbeiner S, Arnold DB, Shaywitz $\mathrm{AJ}$, Greenberg ME: $\mathrm{Ca} 2+$ influx regulates BDNF transcription by a CREB family transcription factor-dependent mechanism. Neuron 1998;20:709-726.

-116 Tabuchi A, Nakaoka R, Amano K, Yukimine M, Andoh T, Kuraishi Y, Tsuda M: Differential activation of brain-derived neurotrophic factor gene promoters I and III by $\mathrm{Ca}^{2+}$ signals evoked via L-type voltage-dependent and N-methyl-D-aspartate receptor $\mathrm{Ca}^{2+}$ channels. J Biol Chem 2000; 275:17269-17275

117 Tabuchi A, Sakaya H, Kisukeda T, Fushiki $\mathrm{H}$, Tsuda $\mathrm{M}$ : Involvement of an upstream stimulatory factor as well as cAMP-responsive element-binding protein in the activation of brain-derived neurotrophic factor gene promoter I. J Biol Chem 2002;277: 35920-35931.

118 Dijkhuizen PA, Ghosh A: BDNF regulates primary dendrite formation in cortical neurons via the PI3-kinase and MAP kinase signaling pathways. J Neurobiol 2005; 62:278-288.

119 McAllister AK, Lo DC, Katz LC: Neurotrophins regulate dendritic growth in developing visual cortex. Neuron 1995;15: 791-803.

120 Horch HW, Kruttgen A, Portbury SD, Katz LC: Destabilization of cortical dendrites and spines by BDNF. Neuron 1999;23:353354.

121 Wirth MJ, Brun A, Grabert J, Patz S, Wahle P: Accelerated dendritic development of rat cortical pyramidal cells and interneurons after biolistic transfection with BDNF and NT4/5. Development 2003;130:5827-5838.

122 Horch HW, Katz LC: BDNF release from single cells elicits local dendritic growth in nearby neurons. Nat Neurosci 2002;5:11771184.

123 Jin X, Hu H, Mathers PH, Agmon A: Brainderived neurotrophic factor mediates activity-dependent dendritic growth in nonpyramidal neocortical interneurons in developing organotypic cultures. J Neurosci 2003;23:5662-5673.

124 McAllister AK, Katz LC, Lo DC: Opposing roles for endogenous BDNF and NT-3 in regulating cortical dendrite growth. Neuron 1997; 18:767-778.

125 Gorski JA, Zeiler SR, Tamowski S, Jones $\mathrm{KR}$ : Brain-derived neurotrophic factor is required for the maintenance of cortical dendrites. J Neurosci 2003;23:6856-6865. 
-126 Xu B, Zang K, Ruff NL, Zhang YA, McConnell SK, Stryker MP, Reichardt LF: Cortical degeneration in the absence of neurotrophin signaling: dendritic retraction and neuronal loss after removal of the receptor TrkB. Neuron 2000;26:233-245.

127 Du J, Feng L, Yang F, Lu B: Activity- and $\mathrm{Ca}^{2+}$-dependent modulation of surface expression of brain-derived neurotrophin factor receptors in hippocampal neurons. J Cell Biol 2000;150:1423-1433.

- 128 Nagappan G, Lu B: Activity-dependent modulation of the $\mathrm{BDNF}$ receptor TrkB: mechanisms and implications. Trends in Neurosci 2005;28:464-471.

129 Kingsbury TJ, Murray PD, Bambrick LL, Krueger BK: $\mathrm{Ca}(2+)$-dependent regulation of TrkB expression in neurons. J Biol Chem 2003;278:40744-40748.
130 Yacoubian TA, Lo DC: Truncated and fulllength $\operatorname{TrkB}$ receptors regulate distinct modes of dendritic growth. Nat Neurosci 2000;3:342-349.

131 Nedivi E, Wu GY, Cline HT: Promotion of dendritic growth by CPG15, an activity-induced signaling molecule. Science 1998; 281:1863-1866.

$>132$ Fujino T, Lee WC, Nedivi E: Regulation of cpg15 by signaling pathways that mediate synaptic plasticity. Mol Cell Neurosci 2003; 24:538-554.

133 Harwell C, Burbach B, Svoboda K, Nedivi E: Regulation of cpg15 expression during single whisker experience in the barrel cortex of adult mice. J Neurobiol 2005;65:8596.

134 Naeve GS, Ramakrishnan M, Kramer R, Hevroni D, Citri Y, Theill LE: Neuritin: a gene induced by neural activity and neurotrophins that promotes neuritogenesis. Proc Natl Acad Sci USA 1997;94:26482653.
135 Yu X, Malenka RC: Multiple functions for the cadherin/catenin complex during neuronal development. Neuropharmacology 2004;47:779-786

136 Vo N, Klein ME, Varlamova O, Keller DM, Yamamoto T, Goodman RH, Impey S: A cAMP-response element binding proteininduced microRNA regulates neuronal morphogenesis. Proc Natl Acad Sci USA 2005;102:16426-16431.

137 Schratt GM, Tuebing F, Nigh EA, Kane CG, Sabatini ME, Kiebler M, Greenberg ME: A brain-specific microRNA regulates dendritic spine development. Nature 2006;439: 283-289.

138 Van Aelst L, Cline HT: Rho GTPases and activity-dependent dendrite development. Curr Opin Neurobiol 2004;14:297-304. 